\title{
“GREAT IDEAS" IN RUSSIAN PSYCHOLOGY: PERSONALITY IMPACT ON PSYCHOPHYSIOLOGICAL FUNCTIONS AND CAUSAL APPROACH TO SELF-DETERMINATION
}

\author{
Irina A. Mironenko \\ Saint-Petersburg University \\ of Humanities and Social Sciences \\ Saint-Petersburg
}

Russian psychology has brought into the world science at least two great ideas: the conditioned reflex (Pavlov) and the zone of proximal development (Vygotsky). These concepts were formulated before "iron curtain" fell. Since then Russian science dropped out from the view of western colleagues for decades. Now it is challenged to re-join international mainstream. Are we in a position to contribute?

A key concept for Russian psychology is personality impact on psycho-physiological functions and causal approach to self-determination. The concept of selfdetermination appeared in Western theories in 1980-es and since then it has been developed in the context of teleological humanitarian approach. In Russian science the concept of self-determination dates back to 1934, when it was defined by Rubinstein as "sub'ekt". Self-determination of ontogenesis of psycho physiological functions resulting from confluence of ontogenesis and social development was explicated by Russian scientists whose theoretical reasoning and empirical results are compared to Western counterparts.

Key words: self-determinatio; causal and teleological approaches; personality impact on psycho physiological processes; psychology in Russia.

Russian psychology has introduced into the world science at least two great ideas: the conditioned reflex (I.P. Pavlov) and the zone of proximal development (L.S. Vygotsky). These concepts were formulated before "iron curtain" fell at the end of 1920-es and so they have become part of the world science. Since then Russian science dropped out from the view of western colleagues for many decades. Now it is challenged to re-join the international mainstream. Are we in a position to contribute or should Russian psychology be treated as a "developing" area of the international science, having no theoretical background of its' own? 
Nowadays psychological science is faced with a boom of facts and figures so it is becoming more and more evident that it is the "great ideas" that matter, concepts which bring reason and logic into the chaos of facts. To be introduced into the world science as an original theoretical trend, it is necessary to come up with original concepts and ideas. Are there any ideas in Russian psychological tradition that can be of interest for the international community?

Behind the iron curtain psychological science was developing. The ideas of Vygotsky and Pavlov inspired new theoretical reasoning and empirical research alongside with ideas still unknown to the international community. Considering "great ideas" in Russian psychology we can mark three types of their relevance to international science:

- Concepts initially integrated into the world science, like Pavlov' and Vygotsky', which were afterwards explicated and developed in different ways in Russia and in the West. Analysis of these developments can promote new understanding in important spheres.

- Concepts mainly unknown for the broad international scientific community but which can be understood as contrapuntal to well known theories. A good example of this kind is Russian evolutionary psychology. Oxford University Press issued a book in 2002: "Infant Chimpanzee and Human Child: A Classic 1935 Comparative Study of Ape Emotions and Intelligence" - that is a paperback of the classic work by N.N. Ladygina-Kots. The fact that it has been returned to the scientific community after a long time obscurity is the evidence of true recognition of Ladygina-Kots's and her colleagues' contribution to the international science. Her works pioneered the new section in psychology - evolutionary psychology. As a Darwinist, she emphasized the evolutionary nature of human cognition and emotion likewise modern Western evolutionary psychologists do. However, as a true representative of Russian psychological tradition she was much concerned with the dialectics of human nature and, therefore, highlighted fundamental differences between animals and human beings alongside with similarities. Her approach radically differs from the approach being developed in modern western science. She always insisted that an ape is in no way human, absolutely not human, rather than not absolutely human. This opposition makes her works particularly valuable for contemporary Western specialists and Oxford republication of her classic monograph acknowledges her contribution.
- Concepts still unknown for the broad scientific community, which might be a "zone of proximal development» for the international science. Among these personality impact on psycho-physiological functions and causal approach to self-determination should be named - key concept for Russian psychological tradition.

The concept of self-determination appeared in Western theories in 1980 -es and since then it has been developed in the context of teleological humanitarian approach, viewed as an intrinsic quality of human being, which can explain human behavior itself beyond explanation. In Russian science the concept of self-determination dates back to 1934, when it was defined by Rubinstein as "subekt" . Self-determination of ontogenesis of psycho physiological functions resulting from confluence of ontogenesis and social development was explicated by Russian scientists. The impact of social and first of all professional personality development on psycho physiological functions was key issue in the works of B.G. Ananjev. Results of his work might turn to be of high topicality in the current research of psychic processes. B.G. Ananjev supposed that human biology itself is a very special type of biology, very flexible and with a very wide range of possible variations. Any epigenetic approach to personality development stresses the crucial importance of environment from the very first stages of life. But during phases of biological growth determined by the biological program of human species the main purpose of environment is just to contribute to optimal development of biological functions underlying human behavior. Since adulthood personality plays the leading role. B.G. Ananjev showed that even further development of biological functions is subjected to it. He argued that functioning of adult human brain itself though it can be described in terms of physiological processes cannot be understood and explained on physiological level because the logic of its' structure and functioning is social. He tried to show that in the course of socialization all psycho physiological functions undergo a general reconstruction so that human brain and human body as a whole becomes an integrate system fit for social functions of the individual. B.G. Ananjev supposed personality to be the key to understanding adult brain functioning. He shared this basic approach with the well known theory of functional brain sys-

${ }^{1}$ Subekt means something like an agent, but always choosing and pursuing his own aims, serving his own purposes: a self-determined agent. 
tems by A.R. Luria. But Luria was more concerned to show the diversity of basic physiological functions that can be used to constitute a certain molar brain system socially determined. Ananjev was more interested in showing effects of social factors on basic psycho physiological functions. In his wide-scale experiments he proved that basic physiological functions that are used in typical forms of social activity (first of all in professional work) keep stable and are even in progress for long, while the functions that are not used are doomed to degrade.

This idea was proved in many experimental investigations (Ananjev, 1960; 1961; Ananjev, Dvorjashina, and Kudrjavceva, 1968). Most impressive are experimental data concerning effects of professional work on life-span dynamics of perceptual abilities. For example, sensitivity to red and yellow colors is normally quickly degrading with age. B.G. Ananjev and his colleagues showed that workers engaged in steel foundries have it stable for long. B.G. Ananjev argued that this is because the workers use their visual color perception to determine the moment when the steel is perfectly ready. So the natural regularity of age dynamics is abrogated. Effects alike were shown concerning stability and progress of other psychophysical functions professionally used: tactile sensitivity, taste discrimination, etc.

One example of this experimental research is an experiment done by B.G. Ananjev's colleague K. Kaufman (Ananjev, Dvorjashina, and Kudrjavceva, 1968) who studied effects of musical professional work on acoustic discrimination. The aim was to show that being a musician not only requires high perceptual abilities as a starting point but in it self is a factor of higherly specialized development of basic psychophysical functions. Acoustic discrimination was measured for three groups of subjects: non-musicians, piano players, violin players. Sounds were presented in pairs, first one was always the same, sound frequency 435 oscillations per second. The second sound was the same or a certain interval higher or lower. Intervals used were $30,23,17,12,8,5,3,2,1,0.5$ oscillations per second. The task was to say whether the second sound was higher, lower or the same as the first one.

At the beginning of their musical education children who chose violin were as good as those who chose piano. The results for grown-up musicians are shown on Figure 1. Circles are for violin players, stars for piano players and crosses mark the results of non-musicians. No wonder that discrimination thresholds are much higher for non-mu-

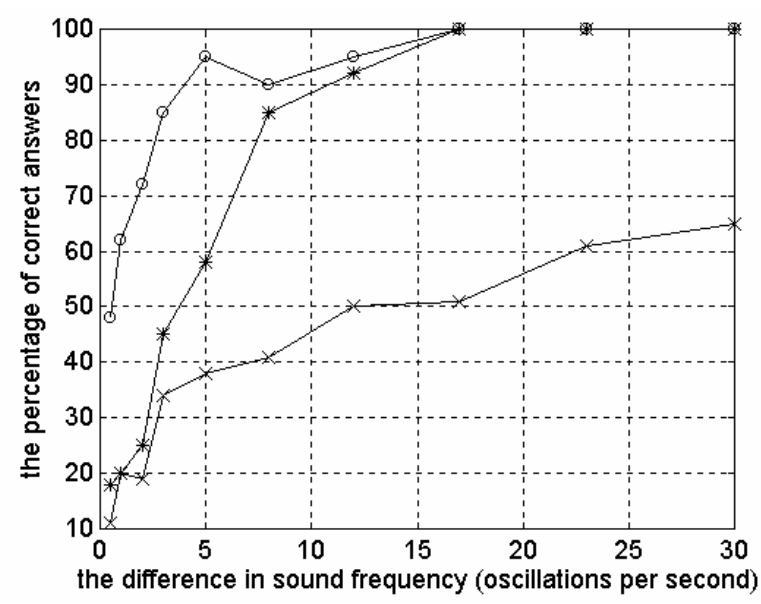

Figure 1. Acoustic discrimination thresholds for three groups of subjects: non-musicians $(\times)$, piano players $(*)$, violin players $\left(^{\circ}\right)$

sicians. Much more interesting is the difference between violin players and piano players. They are doing similarly well as long as the interval between two sounds is not too small. As soon as we come to micro intervals piano players are doing much worse. To explain these results B.G. Ananjev turns to the specific nature of the subject's musical professions. He argued that piano players are working with a "discrete" scale of sounds, with the keyboard, while the violin players have to construct the sound each time, they work with a non-discrete, continuous, scale. That is why the latter professionally use their abilities to discriminate micro intervals and have the relevant perceptual functions stable and in progress while the former don't have to use these and the perceptual functions are degrading.

B.G. Ananjev' work "Sensory-Perceptional Organization of Man" (1977) is structured on the grounds of a passionate argument with the opponents: "A prevalent... idea that sensory-perceptive processes belong to the inferior psychic functions and, being the periphery of human psychic organization, are not included in the main structure and are indifferent to the personality, - should be considered as hopelessly outdated" (Ananjev, 1977, p. 51). B.G. Ananjev insists and proclaims a totally new approach: "sensory-perceptive processes... belong... to the core phenomena of life 
activity connected with deep layers of the holistic structure of human personality development... only sensory-perceptive organization corresponds to man as the whole, as an individual and a personality, it being a unified system of all modalities without exceptions, - and included, in its turn, into the general structure of human development" (Ananjev, 1977, p. 51). We think, that the dichotomy of approaches to the understanding of sensoryperceptive processes suggested by B.G. Ananjev is quite topical nowadays as well (Mironenko, 2005).

In accordance with B.G. Ananiev's concept, the relation of biological and social factors in the process of the individual development gives rise to internal controversies which themselves become the driving forces of individual development. These controversies are considered at the level of psychic processes, and in this structure B.G. Ananjev singles out functional, operational and motivational components (mechanisms).

The development of the functional mechanisms conforms to the laws of ontogenesis. Operational mechanisms develop in the result of assimilation of the cultural and historical experience of humankind. The controversy between the natural psycho-physiological functions and the social operations within the structure of the psychic process is resolved by way of training and structuring of the maturing functions in accordance with the socially generated ways of action, thus, the direction in which the functions develop is defined by the contents of the man's activity and his social behavior.

B.G. Ananjev and his colleagues have shown in large-scale experiments surprising effects of the individualization of the ontogenesis of psycho-physiological functions, first and foremost, sensory-perceptive ones, as the result of the peculiarities of the personality life journey and the formation of the subect (agent) of professional activity; these were described, in particular, in the works "Sensory processes" (1961), "Sensory-Perceptive Organization of Man" (1977) and others. In these works the data are presented that have no analogues in the world's science and that are still actual today. These works up to now remain almost unknown to the foreign colleagues, they are practically not cited in modern research. At the same time, these works might turn up to be extremely topical today, and their currency only increases with new successes in the development of the biological science.

In psychology, starting from antiquity there appear from time to time trends which proclaim that we should aim at the solution of psy- chological problems by way of using methodology and methods of the biological sciences. The history of psychology produces convincing evidence on the usefulness and significance of such research, however, absolutization of this approach in psychology, its extensive usage lead to a dead-end and mean that psychology loses its subject, since the psychic cannot be explained and described in the terms of physiological mechanisms, the same as the building's architecture cannot be described in the terms of characteristics of the bricks used.

Due to its ontological nature, the psychic, whose substratum is the relationship of the subject with the surrounding world, cannot be brought down to physiological mechanisms. The dialectic approach to the problem of correlation of the psychic and the physiological has always been one of the strengths of the Russian psychological theories; up to now the works of Russian scientists in this area have no analogues in the world's science and within the context of development of the Western psychology look like the area of its proximal development. And the issue that direct physiological explanation of sensation and perception is not enough can be heard more and more often in the works of foreign experts on cognitive processes today. It is significant that the main topic of the lecture delivered by Cambridge professor J.D. Mollon at the opening of $29^{\text {th }}$ European Congress on Visual Perception (ECVP, 2006), that brought together psychologists, physiologists and specialists on artificial vision from different countries, was the discrepancy between the physiology of color perception and subjective perception of colors, which is manifested greater and greater with more successful research of physiological mechanisms. "Should not we look for a key to the mystery of color perception outside our body?" (Mollon, 2006), - he asks.

One should mark particularly the significance of the methodology developed by B.G. Ananjev with regard to the tasks in the area of man's work with continually upgrading devices that extend and modify human possibilities to sensuously perceive the surrounding world, first of all visual devices. At present, this area of research has fallen out of the view of the Russian psychologists together with the orders financed by the military-industrial complex. But this problem area continues to exist and can be potentially assimilated only by the psychological science. Anybody, who has ever professionally engaged with research of the work of an observing operator and dealt with complex modern visual devices (e.g. thermal imager), can witness that optimization aimed at the laws 
of the physiological mechanisms' level does not allow to reach success in such tasks. Images of material world on the screen of such a device that are submitted to the operator seem to an inexperienced person to be a chaos of spots. And that cannot be transformed into the familiar picture of the world by way of any standard algorithmic transformation. But gaining more and more experience in the work with such device, the experience of real activity, orientation and moving a field, for example, quite amazingly the person learns to see the material objective world in the images and even act in this world. The way the person learns to see the world on the basis of such images cannot be explained by the response of any innate detectors: there are no such images in nature, they were created by human civilization.

The quicker the advance of technology when man creates himself the new habitat, the more such cases happen; and the more the idea is demonstrated, that was originally declared and substantiated by B.G. Ananiev, the idea of the continuing historical development of the system of human analysers under the influence of civilization; as well as the provision framed by him that one of the factors of further progress of human sensation is the "progressive development of the instruments of labor, and technical means that broaden the field of sensory cognition» (Ananjev, 1977, p. 88). Today, it becomes more and more evident as the progressive development of observation devices for the professional activities of operators not only provides the human operator with more comfort at the level of physiological mechanisms of differentiation of the visual projections, but also sets up higher and higher demands in terms of the human ability to recognize objects of the surrounding world in the images, to understand these images. For the optimization of these devices a research is needed at the level of psychological mechanisms with the participation of psychologists.

Man in B.G. Ananjev's theory stands out as, first, a historically concrete type, specific in its psychic organization in different moments of history; second, as a self-determining creator of one's own self. Not only the level of development attained depends on the human self-determination (which is common for the Western concepts), but also the direction of development.

B.G. Ananjev considers individualization as the most important pattern of human ontogenetic development: "rather significantly the human life journey (biography) influences his ontogenetic evolution via the more and more increasing individualization of this evolution" (Ananjev, 1977, p. 165)

B.G. Ananjev thus stated the provision on two-phase nature of human development during the life span: "In the first phase, general, frontal progress of functions takes place in the course of growth and in the earliest evolutionary changes of maturity" (Ananjev, 1977, p. 201). The laws of ontogenesis play the key role in this period. The second phase differs drastically from the first one; it lasts from the on start of maturity to the end of life, "At the second phase of the functions' evolution, their specialisation ...occurs" (Ananjev, 1977, p.202). This second phase begins at the highest level of functional achievements of the first phase and superimposes it. So the peak of the functional development is reached at later stages of maturity, while "the optimum of specialized functions may coincide with the imminent involution of the general characteristics of the same functions" (Ananjev, 1977, p. 202). There's no supremacy here of the universal generic programme of human development; to be more precise, this development is secured by the exact amount of active forces within the human being that counteract the inevitable ageing. In this connection B.G. Ananjev speaks about divergent and convergent types of development.

Convergent type is characterized by total decrease of functions with ageing, which happens when the psyche's operational and motivational mechanisms are not duly formed in the course of life. In the case of divergent type of ageing, these mechanisms provide stability of psychophysiological functions and even their progressive development manifested in the presence of optimums of function in old age, beyond the limits of biological growth.

Individualization, the increase of individual singularity is the main effect of human development and its measure for B.G. Ananjev. In accordance with his concept, the individual singularity increases with growing up and is an indicator of the general level of development, the abilities included.

The works of B.G. Ananjev clearly show dialectic understanding of human nature. Man, in Ananjev's understanding, is a product of individual psychic development which manifests itself in three expressly separated planes:

- Ontogenetic evolution of the "individual"'s psycho-physiological functions (Man and Nature bias). 
- Life journey of a human being - "personality” - history (Man and Culture bias).

- Development of man's activities and history of his development as a "subect" (agent) of labour, cognition and communication (Man and Civilization bias).

Thus the process of human development is depicted as based on interrelation of different bases separate in their origin: Nature, Culture and Civilization. There's no Universal Law of human development, there's only a number of relatively independent factors, and their influence is mediated and integrated by the individuality of each human being. It's the individuality, personality uniqueness, that defines the vector, direction and route of human development. Individuality from early age manifests itself by refracting and combining the biological individual programme, the socially defined programme of personality development and the programme of formation of the agent of activity. In mature age, individuality factor becomes domineering. Individuality turns to be the result of the integration of natural and cultural development in the course of life activities, which constitutes the holistic structure of human being, bringing to harmony one's tendencies and potentials and determining the structure and development of psycho physiological functions.

B.G. Ananjev derives substructure of an "individual" from the biological characteristics of man, that of a "personality" - from specifically sociological characteristics, and that of an "agent" - from the material basis, tools created by civilization. The species, social medium, and civilization sprout into the human being, and tend to form his psyche, each in accordance with its own laws. And only individuality is in its nature a psychic phenomenon; thus, it is the psychic phenomena that constitute the integrating foundation and nucleus, vector and law of human development.

At the same time, in Western psychology an idea domineers about uniformity of psycho-physiological development laws for every person, alongside with uniform meaningful charging of the personality development phases (E. Ericsson, A. Maslow, et al.). Main theories of personality development: psychodynamic, humanistic and cognitivebehavioral, - traditionally are more concerned with stages of growth, from infancy to youth and are rather in good concordance when assessing these stages. They are nearly the same stating the ages when passing from one phase of life to another occurs. As to the contents of each phase these theories seem more supplementary than alternative to each other, because each of these theoretical approaches is more concerned with a certain domain of development (biological, cognitive, affective or social development) and less concerned with other domains. As for adulthood empirical studies are scarcer and theoretical models less concordant.

Well-known theories of human personality development are mainly aimed to reveal the general regularity of the process, which would account for all human species. So the development is viewed as a sequence of transformations of internal structures which lead through a serious of stages to the structure of adult personality. The main thing in common is the implicit belief that general personality structure is the same for all times and all cultures, determined by the nature of human race, say, biologically. Social aspects of development are considered mainly as factors that can somehow perverse the right way things should be.

This approach can be illustrated by classical works of William James who at the end of the $19^{\text {th }} \mathrm{c}$ argued that a well-bread gentleman is different from a rough factory worker because the former had had his chance to develop his human instincts while the latter had not and his human nature was distorted by social conditions. The same approach we can perceive in the theory of social characters by E. Fromm which appeared nearly a century later and even in modern cognitive theories searching for a sequence of invariant qualitatively different developmental stages.

It should be mentioned, that on the whole the idea about the uniform content of the phases of human development, as well as the idea about the existence of the so called universal values, brings individuality down to individual differences in manifestation of various qualities out of the set which is the same for everybody. One may point out, that quite paradoxically in Western psychology with its cult of individualism the individual freedom acquires the status of epiphenomenon and turns out to be the freedom in choosing means and not targets.

Putting the man at the overlapping of biological laws and cultural regulations like Freud did, unlike Freud Ananjev perceived this dual nature of a human being as a way to individual freedom: freedom from biological restrictions by the law of culture and freedom from cultural restrictions by the law of nature. At the same time Ananjev's theory stands out for it's humanistic appeal for which it is still actual today. Be- 
ing mainly concerned with striking social effects on human biology he was very well aware of the natural limits of this flexibility. He believed the main practical aim of psychological science is to help individual in seeking his unique way of coping with the situation and himself, becoming the agent of his own life and obtaining unique individual harmony being a bio-social creature.

B.G. Ananjev's theory remains in fact unknown to the foreign scientific community. His name is not mentioned in modern foreign encyclopedias or abstract journals. A little part of his works that was translated into foreign languages, was not duly understood or appreciated by the psychologists' community because of the specific notional and conceptual structure used by B.G. Ananjev. The conceptual structure of the theory, the issues discussed do not directly correlate with the categorial structure of the modern foreign psychology, hence, this theory cannot be perceived and integrated by foreign scientists without the special efforts. At the same time, B.G. Ananjev's methodology and theory seem to be fruitful within the intensively developing areas of the world's psychological science provided the system of notions and concepts used is adequately correlated. Among the areas of research and topical issues may be named alongside with the personality impact on psycho physiological functions life-span human development, analysis of development in various age periods from the point of view of the holistic context of human life and age dynamics of maturity.

These are now in the centre of attention of the international psychological science, and its intensively developing branches. The currency of these issues is shown by corresponding articles in encyclopedic editions (Corsini, 1994); and in frequently sited monographs, such as (Merrens, 1996; Papalia, 1995 Santrock, 1997).

The approach to the studying of the laws of development within various life periods from the point of view of the holistic context of the subject's whole life was also formed and put into practice in the works of B.G. Ananjev and his followers. It is interesting, that in psychological Encyclopedia (Corsini, 1994) the idea of uniting different age periods of psycho-physiological development into a common life cycle is characterized as a last achievement of the theoretical thought (Corsini, 1994, p. 166-170).

In the same encyclopedia, the age dynamics of maturity is characterized as a poorly studied and urgent scientific problem. Maturity is tradi- tionally presented as a period of stabilization preceding ageing. In foreign psychology the notion of development is used in the analysis of psychophysiological functions in the period of maturity only in the meaning of adaptation, adjustment of mainly set structures to certain conditions of existence. B.G. Ananjev considered maturity as a period of complex dynamic changes in all psycho-physiological human structures.

In the works of B.G. Ananjev the following peculiarities inherent to the Russian psychology of the natural science direction have been manifested:

- Determinism in the view of the formation of human individuality, which becomes a logical result of the development of man with natural characteristics inherent to him in concrete historical situation;

- Objective scientific method of research of the individuality, obligatory use of biographical methods and self-observation alongside the experimental methods;

- Integrated consideration of personality and organismic phenomena, understanding that man «is not only a heart and soul, but also a substratum, that lives according to all laws of material development and changes it's own potentials when entering one or other system of social relationships» (Loginova, 2005, p. 264).

Thus, B.G. Ananjev' and his colleagues' view on human development and human nature seems to be deeply and truly original in the context of approaches developed in Western science; it has no analogues within this science and has a significant polemic potential secured by a powerful foundation of empirical proofs.

Becoming a part of the worldwide science after a long period of isolation behind the "iron curtain" nowadays implies a challenge for Russian psychology:

- Should it be regarded as a school, non-derivable from other theoretical approaches and self-consistent,

- or should it be viewed as a "developing" area of the international science, having no theoretical background of its' own?

Of course there is no chance and no need for Russian psychology to preserve its mono methodological trend. Many of Russian psychologists today cling to other theoretical approaches. Nonetheless, I believe that the scientific tradition that was developed behind the "iron curtain" can still contribute substantially to the development of the world science, can become an integrate but specific part in the structure of interna- 
tional psychology. I believe there are great ideas in Russian psychological tradition that can be of interest for the international community and causal approach to self-determination is one of them.

\section{References}

Ananjev, B.G. (1960). Psikhologiya chuvstvennogo poznaniya [Psychology of sensory processes]. Moskva.

Ananjev, B.G. (1961) Teoriya oshhushhenij [Sensory processes]. Leningrad.

Ananjev, B.G. (1968) Chelovek kak predmet poznaniya [Man as a subject of investigation]. Leningrad.

Ananjev, B.G. (1977). Sensorno-perceptivnaya organizaciya cheloveka [SensoryPerceptive Organization of Man]. In B.G. Ananjev. O problemakh sovremennogo chelovekoznaniya [Current problems of Human understanding]. Moskva.

Ananjev, B.G., Dvorjashina, M.A., and Kudrjavceva, N.A. Individual 'noe razvitie cheloveka $i$ konstantnost 'vospriyatiya [Perceptual constancy in the course of human lifetime development]. Moskva.

Corsini, R.J. (ed.) (1994). Encyclopedia of Psychology. Vol.1-4. New York: Wiley \& sons, cop.

Loginova, N.A. (2005). Opy't chelovekoznaniya [Experience of human understanding]. Saint-Petersburg.

Merrens, M.R. (1996). The developmental psychologists: Research adventures across the life-span. New York: McGraw-Hill.

Mironenko, I.A. (2005) Biosocial 'naya problema v sovremennoj psikhlogii i perspektivy' razvitiya otechestvennoj teorii [Biosocial problem in the context of current psychological science]. Psikhologicheskij zhurnal, 1. P. 88-95.

Mironenko, I.A. (2008). On Some Difficulties in the Dialogue with Foreign Colleagues. In Y. Zinchenko, and V. Petrenko (eds.). Psychology in Russia: State of the Art. Moscow: Department of Psychology MSU \& IG-SOCIN. P. 41-47.

Moghaddam, F.M. (2005). Great ideas in psychology. Oneworld, Oxford.

Mollon, J.D. (2006). The Perception. Lecture. Perception, 35.

Papalia, D.E., Olds S.W. (1995). Human development. New York: McGraw-Hill.

Santrock, J.W. (1997). Life-span development. Dubuque (Iowa): Brown. 